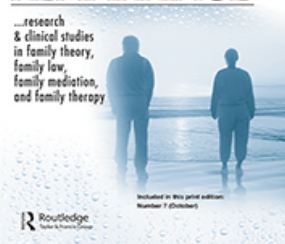

\title{
Parent-Child Communicational Characteristics: A Comparison Study between Subjects from Post- Divorce and Intact Nuclear Families
}

\section{Alda Patrícia Marques Portugal \& Isabel Maria Marques Alberto}

To cite this article: Alda Patrícia Marques Portugal \& Isabel Maria Marques Alberto (2019) Parent-Child Communicational Characteristics: A Comparison Study between Subjects from Post-Divorce and Intact Nuclear Families, Journal of Divorce \& Remarriage, 60:7, 566-582, DOI: 10.1080/10502556.2019.1627163

To link to this article: https://doi.org/10.1080/10502556.2019.1627163

\section{Published online: 14 Jun 2019.}

\section{Submit your article to this journal $\sqsubset$}

Џ Article views: 1023

a)

View related articles $\sqsubset$

View Crossmark data \lceil 


\title{
Parent-Child Communicational Characteristics: A Comparison Study between Subjects from Post-Divorce and Intact Nuclear Families
}

\author{
Alda Patrícia Marques Portugal (10) ${ }^{a, b}$ and Isabel Maria Marques Albertoc \\ aDepartment of Psychology, Faculty of Arts and Humanities of University of Madeira, Funchal, Portugal; \\ ${ }^{\mathrm{b}}$ Center for Social Studies of the University of Coimbra, Coimbra, Portugal; ' $F a c u l t y$ of Psychology and \\ Educational Sciences of University of Coimbra, Coimbra, Portugal
}

\begin{abstract}
The occurrence of divorce seems to have impact on parentchild communication, with subsequent implications on the children well-being and development. The present study aims to analyze the influence that divorce has on parent-child communication comparing 102 participants from postdivorced families and 100 participants from intact nuclear families. Measures consisted of a sociodemographic questionnaire and Perception Scale of Parenting Communication. Despite literature indicators, the main findings reveal the absence of significant statistical differences between both family structures, concerning to parent-child communication. Overall, it was registered some statistically significant differences concerning to specific divorce variables. These findings demystifying the idea that post-divorce families establish less positive communication patterns when compared with intact nuclear families.
\end{abstract}

\section{KEYWORDS}

Parent-child

communication; postdivorce families; intact nuclear families; school-age children; adolescents

\section{Introduction}

According to Segrin and Flora (2005), communication is defined as "a transactional process from which individuals create, share and regulate meanings" (p. 15). In family context, communication enables one to identify, comprehend, and respond to the specific needs of each member during the life cycle (Carr, 2006), determining specifically how parenting will take place (Herbert, 2004), in order to promote the well-adjusted development of children (Bornstein, 2002; Rivero-Lazcano, Martínez-Pampliega, \& Iraurgi, 2011).

According to Pragmatics of Human Communication (Watzlawick, Beavin, \& Jackson, 1967/1993), it is impossible not to communicate, that is, all communication is behavior and all behavior translates a communicative intention. Based on this premise, it becomes difficult to operationalize the dimensions that integrate and characterize the parent-child communication.

CONTACT Alda Patrícia Marques Portugal alda.portugal@staff.uma.pt 0 Faculty of Arts and Humanities of University of Madeira, Colégio dos Jesuítas - Rua dos Ferreiros 9000-082 Funchal, Portugal 
In this, Portugal and Alberto $(2013,2014)$ conducted some studies with parents, adolescents and school-age children with a purpose of identifying the main characteristics of parent-child communication. The results of these investigations highlighted as dimensions of parent-child communication: (a) emotional support/affective expression (involves the exchange of positive messages between family members and refers to characteristics of communication, such as clarity, effective problem solving, supportive statements and demonstration of empathy); (b) parental availability to communication (reflects willingness to answer questions, having an open-minded attitude, balancing openness with privacy and being responsive to particular characteristics); metacommunication (refers to the extent to which parents are able to communicate about communication with their children); (d) parental and children confidence/sharing (refers to sharing personal problems and intimacy issues, both from the parent and child's perspectives; it is related to work, relationships, friendships, family; sharing issues should be balanced with an individual's own privacy); and (e) negative communication patterns (focused on the negative aspects of communication, such as hesitancy to share, negative styles of interaction and selectivity and caution in what it is shared) (Portugal \& Alberto, 2013, 2014).

Although these characteristics tend to remain more or less stable during the family life cycle (Laursen \& Collins, 2004), there are events (normative and/or accidental) that can cause changes in parent-child communication and that will reflect on the quality of the relationship between parents and children. In this sense, changes in family structure as a result of a divorce can have significant effects on communication between parents and children (Afifi, Huber, \& Ohs, 2006; Afifi, Granger, Joseph, Denes, \& Aldeis, 2014; Eldar-Avidan, Haj-Yahia, \& Greenbaum, 2009; Herzog \& Cooney, 2002; Lewis, Wallerstein, \& Johnson-Reitz, 2004; Linker, Stolberg, \& Green, 1999; McManus \& Nussbaum, 2011). When family structure undergoes significant changes, typical communication processes of that family are also likely to change since divorce represents the need for restructuring and reorganization (Carr, 2006; Segrin \& Flora, 2005).

The literature qualifies divorce as being an accidental crisis (Peck \& Manocherian, 1995) and a painful and disruptive family process, as much so for the parents as for the children (Afifi et al., 2006). Separation and divorce rates increased sharply over the last three decades in Europe as a result of the transformations in which society, families, and marriages have passed (Torres, 2010). According to Eurostat (2018), approximately 2.2 million marriages and 946 thousand divorces took place in Europe in 2015. These figures may be expressed as 4.3 marriages for every 1000 persons (crude marriage rate) and 1.9 divorces for every 1000 persons (crude divorce rate). Studies have been conducted with the purpose of analyzing the impact of divorce on family relationships. Bing, Nelson, and Wesolowski (2009) 
found that one of the relevant variables to understand the impact that the divorce has in the short term (i.e., 6months after divorce) on the adjustment of children to parental separation, concerns the level of involvement with the Court. According to the authors, the greater the involvement of the family with the Court to address aspects related to divorce and children custody, the lesser will be the favorable divorce conditions, the child coping ability, as well as the positive divorce resolution and the levels of external supports. Thus, the authors consider that the level of involvement with the Court reflects the family conflict, that is, the greater the involvement, the greater the level of marital conflict. The literature also shows that these adverse effects may extend over time. For instance, the study by McManus and Nussbaum (2011), in order to identify the parameters of the stressors associated with divorce (e.g., concerns related to rebuilding the family, financial issues, sharing of time, communication, conflict management), shown that 10 years after the separation, families continue to experience some of these problems, suggesting that the divorce consequences may be felt in the long term.

Although a significant part of the literature emphasizes the less positive aspects and the risks that divorce represents for the exercise of parenting, one must not overlook certain possible advantages which this event may bring to parental relationship as well as to parent-child interaction. Lambert (2007) carried out a qualitative study that analyzed the young adults' perceptions of their parents' divorces, identifying some advantages (e.g., greater resistance to bear the crisis, closer ties to siblings and other family members, perception that parents are now happier individuals, knowing what not to do in an intimate relationship, perception of greater attention or care received from each of the parents, less tension and stress in the family, increase in one's personal social network) and some disadvantages (e.g., difficulty when defining visits/holidays with each parent, lack of an uniform parental model, hostility between the parents, decrease in economic conditions). The results of the literature review made by Lansford (2009) corroborate these findings, demonstrating that although divorce has an immediate negative impact on children's academic performance and behavior, the majority of young people whose parents have divorced do not present this type of problem over time.

In spite of the existence of some studies about divorce effect on family dynamics, research is scarce specifically in what concerns the relationship between divorce and parent-child communication (Ferraro, Davis, Petren, \& Pasley, 2016). Recently, Supratman (2017) highlighted the confusion adolescents experienced in communicating with both parents at the beginning of the divorce, and suggested that effective interpersonal communication immediately started to shape after the single parents succeed to adapt to a new social family pattern. Nevertheless, the author emphasizes the paradigm shift in looking at the value of the family unit, considering that the stigma in 
divorced families is no longer seen negatively, thus facilitating the adjustment of parent-child communication to the new family configuration.

Cohen, Leichtentritt, and Volpin (2012) also designed a qualitative study focused on mothers' subjective experiences of communication about, not only what they choose to disclosure and to hide from their children, but also the feelings, concerns, and perceptions that drove their communication. A main result highlighted from this study is that mothers feel the obligation to maintain a good fatherly image on the communication with their children and, also, they wish to preserve a strong maternal figure. In any case, study participants highlighted the importance to maintain the well-being of their children and, consequently, to adjust communication patterns in a postdivorce stage toward that goal. The authors suggest that further studies should analyze which sociodemographic variables influence divorce-related communication. Another qualitative study conducted by Markham, Hartenstein, Mitchell, and Aljayyousi-Khalil (2017), with the purpose of analyzing the communication among parents who share physical custody after divorce, concluded that share physical custody doesn't improve coparental communication by itself; what seems to really matter in the improvement of coparental communication is parental decision about exercising or not the share physical custody.

The literature so far presents, however, two main limitations: (a) the existing studies are more focused on a retrospective design, ignoring the family reorganization phase which takes place immediately after the divorce, and (b) most of the studies are based on a qualitative approach and, consequently, analyze small-scale samples (about 10-20 subjects). In addition to these constraints, there is a gap in literature research, specifically about parent-child communication and family divorce. For these reasons, the present study proposes to compare the parent-child communication perceived by parents and children from intact nuclear families and by parents and children from post-divorce families, in order to identify how family structures differ in the degree to which they use several communication characteristics (those conceptualize by Portugal \& Alberto, 2014). Since divorce tends to occur in marriages between 10 and 30 years of living together (Eurostat, 2018), this study will focus on two distinct family life cycles, namely, families with school-age children and families with adolescent children. We posed the following three research questions:

$\mathrm{RQ}_{1}$ : Is there any statistical differences in parent-child communication characteristics between post-divorce and intact nuclear families' participants? If so, in what dimensions do these differences occur?

$\mathrm{RQ}_{2}$ : Is there any statistical differences in parent-child communication characteristics according to the sociodemographic variables of the 
participants, namely gender and family structure (single parents with and without child custody and subjects of reconstituted families with and without child custody)?

$\mathrm{RQ}_{3}$ : Are there any statistical differences in parent-child communication specifically in post-divorce participants according to divorce process variables (divorce years and nature of divorce process at Court)?

\section{Materials and method}

\section{Sample}

The sample consisted of 202 participants ( $n=55$ fathers, 75 mothers, 41 sons, and 31 daughters) distributed over two subsamples: 102 participants from post-divorced (PD) families and 100 participants from intact nuclear (IN) families. A chi-square test was performed to compare the proportion of cases from each family condition, having not found statistically significant differences between the two subgroups $\left[X^{2}(1, N=202)=.02, p<.88\right]$. This means that the proportion of participants in each condition was not significantly different in terms of their family structure.

Specifically, the subsample of PD subjects consisted of 29 fathers (28.4\%), 39 mothers (38.2\%), 19 sons (18.6\%) and 15 daughters (14.7\%). The parents' ages varied from 23 to 60 years $(M=41.72, S D=7.90)$ and the children's ages ranged from 7 to 16 years $(M=11.41, S D=2.84) ; 16(47.1 \%)$ of the sons/ daughters were school-aged children (7-11 years old) and 18 (52.9\%) were adolescents (12-16 years of age). As for the level of education obtained by the parents, nine parents (13.2\%) had only reached elementary school, eight $(11.8 \%)$ had completed the $6^{\text {th }}$ grade, $15(22.1 \%)$ completed the $9^{\text {th }}$ grade, $22(32.4 \%)$ had concluded their secondary education $\left(10^{\text {th }}\right.$ to $12^{\text {th }}$ grades $)$, and $14(20.6 \%)$ obtained a university degree. As for the sons/daughters, 10 children (29.4\%) were still in the beginning of the elementary school, 9 $(26.5 \%)$ were in the $5^{\text {th }}$ and $6^{\text {th }}$ grades, $11(32.4 \%)$ were in the $7^{\text {th }}$ to $9^{\text {th }}$ grades and $4(11.8 \%)$ were senior high school teenagers $\left(10^{\text {th }}\right.$ to $12^{\text {th }}$ grades $)$.

In terms of socioeconomic status, it was verified by means of calculations based on indicators on the parents' professions and available income of the INE (Portuguese Statistics) that the majority of the parents belonged to the socioeconomic middle class $(n=46,67.6 \%)$, followed by lower socioeconomic class $(n=20,29.4 \%)$ and upper socioeconomic class $(n=2,2.9 \%)$. In what concerns family structure, 62 participants $(60.8 \%)$ belong to singleparent families with child custody, 19 (18.6\%) to single-parent families without child custody, 15 (14.7\%) to reconstituted families with child custody and $6(5.4 \%)$ participants belong to reconstituted families without child custody. 
In terms of Court procedural information, the divorce process of most of the participants $(n=66,64.7 \%)$ report to the last 3 years and $36(25.5 \%)$ report to more than 6 years. The majority of the PD subjects are in a custody regulation process (that is, parents negotiate practical aspects about parental responsibilities after divorce at the Court; e.g., decided at Court who will bear major parental responsibilities $(n=54,52.9 \%)$. Twenty-eight $(27.5 \%)$ are in a default custody process (that is, parents attempt to settle some incompatibilities about previous custody arrangement proposed by Court; e.g., parents didn't pay the financial amount agreed in Court of their child), and 20 (19.6\%) are in a custody amendment process (that is, the Court has proposed changing some aspects of their previous agreement; e.g., asking children to spend the night with the nonresident parent). Among these participants, 84 $(82.4 \%)$ still have their case in process and $18(17.6 \%)$ already have a Court decision.

The subsample of IN families consisted of 26 fathers (26\%), 36 mothers (36\%), 22 sons (22\%) and 16 daughters (16\%). The parents' ages ranged from 25 to 51 years $(M=40.49, S D=3.33)$ and the sons/daughters were aged 7 to $16(M=10.87, S D=2.05), 23(59 \%)$ are being school-aged children (7-11 years old) and $16(41 \%)$ are adolescents (12-16 years old). As for the level of education obtained by the parents, 6 parents $(9.8 \%)$ had only concluded the $4^{\text {th }}$ grade, $11(18 \%)$ had completed the $6^{\text {th }}$ grade, $17(27.9 \%)$ completed the $9^{\text {th }}$ grade, $11(18 \%)$ had concluded their secondary education $\left(10^{\text {th }}\right.$ to $12^{\text {th }}$ grades), and finally 16 (26.2\%) obtained a university degree. As for the sons/ daughters, 14 children (35.9\%) were still in the first four Grades, 12 (30.8\%) were in the 5 th and 6th grades, $10(25.6 \%)$ were in the 7 th to 9 th grades and 3 $(7.7 \%)$ were Senior High school teenagers $\left(10^{\text {th }}\right.$ to $12^{\text {th }}$ grades). In terms of socioeconomic status, the majority of the parents belonged to the socio economic middle class $(n=47,75.8 \%)$, followed by the lower socioeconomic class $(n=7,11.3 \%)$ and the upper socioeconomic class $(n=8,12.9 \%)$.

\section{Measures}

Data collection was carried out with recourse to two instruments (approximately 20-min paper-and-pencil questionnaire): a sociodemographic data sheet and the three versions (child, adolescent, and parent) of the Perception Scale of Parenting Communication (COMPA). The sociodemographic data sheet dealt with information related to participants' variables, such as gender, age, completed study years, life cycle stage, socioeconomic status, and family structure. In the specific case of the PD sample, the socio demographic data sheet also looked for information on legal procedures, such as process typology (for example, amendment of parental responsibility or regulation of parental responsibilities), length of the process in years and stage of the proceedings (any Court decision on the process). 
The Perception Scale of Parenting Communication (COMPA; Portugal \& Alberto, 2014) is a self-report instrument that evaluates communication characteristics between parents and children using a 5-point Likert scale $(1=$ Never, $5=$ Always). In the present study, the versions for parents, for children aged 7 to 11 , and for adolescents aged 12 to 16 were used. Both the child and adolescent versions included the same items, one to be answered regarding the mother and another one to be answered regarding the father. The parental version (COMPA-P) has 44 items distributed over five subscales (emotional support/affective expression, parental availability to communication, metacommunication, parental confidence/sharing, children confidence/sharing). In the original validation study, the subscales registered values of internal consistency between $\alpha=.52$ and $\alpha=.86$ and in the present study, the values range from $\alpha=$ .47 to $\alpha=.89$. The version for children aged 7 to 11 (COMPA-C) has 16 items distributed over two subscales (parental availability to communication, emotional support/affective expression); in the original study, the two subscales presented values of internal consistency between $\alpha=.76$ and $\alpha=.86$ and in the present study the values range from $\alpha=.80$ to $\alpha=.98$. Finally, the COMPA-A version for adolescents aged 12 to 16 consists of 39 items distributed over five subscales (parental availability to communication, children confidence/sharing, emotional support/affective expression, metacommunication, negative communication patterns), showed values of internal consistency between $\alpha=.62$ and $\alpha$ $=.87$ in the original study and in the present study the values range from $\alpha=.32$ to $\alpha=.89$. Although internal consistency values are very similar to those obtained in the original study (Portugal \& Alberto, 2014), in the present study certain coefficients for Cronbach's $\alpha$ were found to be less than $\alpha=.70$ for some scales, which is considered low according to the literature (Nunally, 1978). Thus, the results of the present research should entail a certain amount of precaution. The negative communication patterns dimension, with respect to mothers (COMPA-A) in the subsamples of IN families, which obtained $a=$ 0.32 , was not subject to analysis.

\section{Procedure}

The study was conducted in Portugal, specifically in Coimbra and Oporto. After the project was submitted to the Núcleos de Infância e Juventude do Instituto da Segurança Social (Nucleus for Children and Youth of the Social Security Institute), authorization was requested for data collection from PD families' subjects. These organizations provide support to Juvenile and Family Courts, facilitating answers to parenting questions when families are in the process of determining child custody and other child protection issues. The research and its objectives were presented to the staff that composed these teams, who in turn informed the PD families' subjects to ensure them of the independence of the research, 
meaning that no connection would be made to any process potentially pending in the Court. In cases where PD subjects agreed to cooperate (requiring a signed informed consent declaration), the measures were applied by a research team member in a room provided for data collection. The selection of subjects was made considering two aspects: (a) the availability of the team member to be in the organizations on the same day that the subjects arrived there; and (b) the voluntariness of the participants to collaborate with the present study (either by completing the measures themselves or by authorizing the minor children to participate in the investigation; in this case, a member of the research team helped the school children to fill the instruments). Thus, the parents/children of the PD sample collection were based on a convenience process. Data collection for parents/children of the IN families sub-sample was also performed through a convenience sampling process that evolved in the snowball technique, that is, the first subjects to whom the measures were applied suggested others available to participate. After the presentation of the project and the receipt of the Informed Consent Form, the measures were applied individually in a quiet place. A member of the research team helped the schoolchildren complete the measures when they had any doubts.

All procedures performed in this study were in accordance with the ethical standards of the institutional and/or national research committee and with the 1964 Helsinki declaration and its later amendments. Participants received information about the research and assurance of confidentiality, as well as the right to terminate their collaboration, if they so wished, without suffering any kind of consequences. After clarification of any questions regarding the study, informed consent was obtained from all individual participants included in the study. As for the children and adolescents, before obtaining their own consent, the authorization of their parents was necessary. Data collection for the sample occurred over a period of 12 months.

\section{Statistical analysis}

The analysis of the normality of the distribution and the homogeneity of the variances showed that these conditions were not satisfied for the variables analyzed in the present study, namely: family structure, participant gender, and variables of the divorce process (years of divorce and the nature of the divorce process). For this reason, non-parametric tests were used, specifically the Kruskal-Wallis and Mann-Whitney tests. 


\section{Results}

RQ1: Is there any statistical differences in parent-child communication characteristics between post-divorce and intact nuclear families' participants? If so, in what dimensions do these differences occur?

The results did not show any statistically significant differences with regard to communication characteristics in the opinion of parents, schoolaged children and adolescents from IN and PD subsamples.

$R_{2}:$ Is there any statistical differences in parent-child communication characteristics according to the sociodemographic variables of the participants, namely gender and family structure (single parents with and without child custody and subjects of reconstituted families with and without child custody)?

Regarding the variable gender, in the subsample of parents/children from PD families, the results have shown that mothers perceived greater parental confidence/sharing $(M d n=38.60)$ than fathers [ $(M d n=28.64), U=396.00$, $z=-2.049, p=.040$ ], and also more emotional support/affective expression $(M d n=39.11)$ than fathers $[(M d n=27.91), U=373.50, z=-2.305, p=$ $.021]$. In relation to the children, only adolescents revealed statistically significant differences in parent-child communication regarding mothers. Adolescents girls perceived greater mother availability to communication $(M d n=14.20)$ than adolescent boys [ $(M d n=6.83), \mathrm{U}=4.00, z=-2.744$, $p=.006]$, and also perceived better mother emotional support/affective expression $(M d n=12.80)$ than adolescent boys [ $(M d n=7.42), U=11.00$, $z=-2.023, p=.043$ ] (see Table 1).

Table 1. Statistical differences in parent-child communication characteristics according to participants sex (U Mann-Whitney Test).

\begin{tabular}{llrrrrr}
\hline PD participants & \multicolumn{1}{c}{ Mdn } & $U$ & $p^{*}$ \\
\hline & \multicolumn{1}{c}{ COMPA's Version } & Male & Female & \\
\hline Parental confidence/sharing & COMPA-P & 68 & 28.64 & 38.60 & 396.00 & .040 \\
Emotional support/affect & COMPA-P & 68 & 27.91 & 39.11 & 375.50 & .021 \\
Availability to communication & COMPA-A (in relation to mother) & 17 & 6.83 & 14.20 & 4.00 & .006 \\
Emotional support/affect & COMPA-A (in relation to mother) & 17 & 7.42 & 12.80 & 11.00 & .043 \\
IN participants & & & & & & \\
Availability to communication & COMPA-C (in relation to mother) & 22 & 8.68 & 14.32 & 29.50 & .035 \\
Availability to communication & COMPA-C (in relation to father) & 22 & 8.45 & 14.55 & 27.00 & .024 \\
Emotional support/affect & COMPA-C (in relation to mother) & 22 & 7.68 & 15.32 & 18.50 & .006 \\
\hline${ }^{*} p<0.05$. & & & & & &
\end{tabular}


In the sub-sample of parents/children of IN families, only school-age children revealed statistically significant differences between girls and boys in parent-child communication regarding mothers. School-age girls perceived greater availability of the mother for communication $(M d n=14.32)$ than boys of school age [ $(M d n=8.68), U=29.50, z=-2.109, p=.035]$, and also greater availability of the father for communication $(M d n=14.55)$ than the school-age boys [( $M d n=8.45), U=27.00, z=-2.261, p=.024]$. Furthermore, school-age girls tended to perceive greater emotional support/affective expression of their mothers $(M d n=15.32)$ than school-age boys [ $(M d n=7.68), U=18.50, z=-2.769, p=.006]$ (see Table 1$)$.

As to the family structure variable, only the results of the sub-sample of the parents were considered statistically significant, since the size of the children subsample was too small for each category of family structure (that is, single parents with child custody, single parents without child custody, parents of families reconstituted with child custody, parents of reconstituted families without child custody and IN families). Using the nonparametric Kruskal-Wallis Test, it was found that the main statistically significant differences occurred between single parents with custody of children and parents of reconstituted families without child custody. Parents of single-parent families with child custody tended to perceive better emotional support/affective expression $\left[X^{2}(4, n=68)=13,052, p=.011\right]$, metacommunication $\left[X^{2}(4, n=68)=14,992, p=.005\right]$, parental confidence/sharing $\left[X^{2}(4, n=68)=14.929, p=.005\right]$ and children confidence/sharing $\left[X^{2}(4\right.$, $n=68)=14.037, p=.007$ ] communication dimensions, compared to parents of reconstituted families without child custody (see Table 2).

$R Q_{3:}$ Are there any statistical differences in parent-child communication specifically in post-divorce participants according to divorce process variables (divorce years and nature of divorce process at Court)?

In what concerns the years of divorce, the results obtained did not show any statistically significant differences in the communication characteristics in the opinion of parents, school-age children and adolescents. However,

Table 2. Statistical differences in parent-child communication characteristics, specifically in PD participants, according to family structure (Kruskal-Wallis Test).

\begin{tabular}{llcrrrr}
\hline & COMPA's Version & $N$ & \multicolumn{2}{c}{ Mdn } & $H$ & $p^{*}$ \\
\hline Emotional support/affect & & \multicolumn{3}{c}{ SPCC } & PRFC \\
Metacommunication & COMPA-P & 68 & 75.51 & 31.58 & 13.052 & .011 \\
Parental confidence/sharing & COMPA-P & 68 & 70.36 & 34.58 & 14.992 & .005 \\
Children confidence/sharing & COMPA-P & 68 & 78.24 & 26.83 & 14.929 & .005 \\
\hline
\end{tabular}

${ }^{*} p<0.05 ;{ }^{* *}$ single parents with child custody; ${ }^{* * *}$ parents from reconstituted families without custody. 
some statistically significant differences were found in relation to the nature of the process: a statistically significant difference in the availability of communication by school-age children was found. That is, school-age children tended to perceive less communication availability by the mother during a custodial regulation process [ $(M d n=6.45), X^{2}(2, n=17)=$ $7.100, p=.029$ ], comparing to school-age children in an amendment regulation $(M d n=13.50)$ and default custody process $(M d n=12.30)$.

\section{Discussion}

The theoretical literature considers divorce an unintended event which may disrupt both the individual's and the family's ability to function and communicate (Afifi et al., 2006; Peck \& Manocherian, 1995). A few studies about this problematic are available; however, there is a gap in research specifically about parent-child communication and divorce. For these reasons, the analysis of the relationship between parent-child communication and divorce has become a necessary issue today.

The present study reveals a surprising result, to the extent that there are no statistically significant differences between participants of PD families and participants of IN families at the level of the communicational characteristics. That is to say, in none of the analyzed stages of the life cycle, it was found that the PD families present more communication difficulties than the IN families. Somehow this result contrasts with much of the literature that suggests divorce as an accidental event with negative impact on the dynamics and on parent-child relationship (Afifi et al., 2006; Afifi et al., 2014; EldarAvidan et al., 2009; Herzog \& Cooney, 2002; Lewis et al., 2004; Linker et al., 1999; McManus \& Nussbaum, 2011).

Laursen and Collins (2004) consider that the quality of parent-child communication tends to be stable over time, since communication fluctuations occur essentially due to the main challenges that arise during the family life cycle. The absence of statistically significant differences between IN and PD subjects may be due to the fact that communication characteristics prior to divorce promoted close ties between family members. This hypothesis suggests that parent-child communication could remain stable and should be analyzed as a process that promotes adjustment to the unexpected lifetime crisis (e.g., divorce), although the magnitude of family communication changes according to previous family history (Allen \& Land, 1999). In other words, the characteristics of communication tend to adjust to the challenges of the parent-child relationship, but regardless of this, the characteristics of communication tend to reflect the parent-child relationship prior to divorce.

Furthermore, society gradually tends to accept the divorce as a regular event (e.g., Ferraro et al., 2016; Supratman, 2017), which is reflected in the 
increase of the divorce's rate in the last three decades (Torres, 2010). This increase must be related to social, family and marital changes. Obstacles to divorce have been substantially weakened by socioeconomic changes linked to industrialization, urbanization and the recognized active role of women in society. These social transformations could, in part, justify the absence of statistically significant differences between parents/children of PD and IN families. The family is now recognized as a competent system for dealing with divorce, reducing the stigmatization and mismatch social representation of these families (Supratman, 2017). It is generally assumed that in the last four decades, and considering the trivialization of divorce, society has implemented strategies to promote the integration of PD families into social interaction, reducing the deficient perspective on the composition of these families (Torres, 2010).

Regarding the eventual effect of gender and the family structure of the participants, some statistical differences between the subsamples were registered. Girls of IN families tended to perceive more father and mother availability for communication compared to boys, and more emotional support/affective expression on the part of their mothers. These results coincide with what the literature suggests about the existence of gender differences in parent-child communication (e.g., Parra \& Oliva, 2002; Portugal \& Alberto, 2014; Wilson \& Koo, 2010). The social representations that favor stereotypes in relation to parental figures may justify these results: the literature observes that, traditionally, children of both sexes tend to seek their mothers when addressing intimate subjects while fathers are more sought for communication of an instrumental nature (McHale, Crouter, \& Whiteman, 2003). We also found statistically significant differences in gender in parents/children of the PD sub-sample: mothers tended to perceive more confidence/sharing and emotional support/affective expression than fathers. Furthermore, adolescent girls noticed more mother availability to communication than adolescent boys.

According to some authors (e.g., Cohen et al., 2012; Fitzpatrick \& Marshall, 1996), mothers tended to initiate more frequent interactional communications with their children, for instance, about their daily routines. This may justify a more active maternal perception. In line with McNaughton (2000), mothers' initiative to communicate may influence adolescent girls' interactions, promoting a mother-daughter communication role based on empathy. Fitzpatrick and Marshall (1996) refer that, in general, adolescent girls tend to receive more affection and verbal communication from their parents compared to boys. This result is also understandable when one considers that the present sample of PD families is composed of mothers who have custody and therefore spend more time with their children.

Specifically, in PD subsample single-parents with child custody tended to perceive communication with their children as more emotional support/ 
affective expression, metacommunication, parental confidence/sharing, and children confidence/sharing compared to parents of reconstructed families without children custody. Considering that COMPA scale highlights specially the communication frequency, it is expected that parents who are not living with their children (parents without children custody) spend less time with them and, thus, perceive less communication interaction in comparison to parents whom have their children custody (Furstenberg \& Nord, 1985). According to Amato, Loomis, and Booth (1995), divorce generally indicates a decrease in contact between children and non-resident parents, that is, those who do not have custody. A possible aspect that could restrain contact from parents without child custody is the relationship maintained the parental partners with child custody. In conflictual child custody process, the interactions between children and non-resident parents tend to be scarce (Furstenberg \& Nord, 1985; Herzog \& Cooney, 2002; Markham et al., 2017). This is an even more relevant aspect if we consider that the majority of the subjects of the PD sub-sample participating in the present study are in the process of custody regulation in Court, showing difficulties in their negotiation process (as suggest by Bing et al., 2009). Markham et al. (2017) suggest that the judicial proceedings of custody arrangement by the parental couple after the divorce process tends to introduce rigidity into their communication process and restrain the communication characteristics established with their children.

As the custody process of parents/children of PD subsample was held in court, it was considered relevant to analyze in what way inherent variables of divorce process influence parent-child communication. One of the most surprising results shows the absence of statistically significant differences in relation to years after divorce. It was expected that parent-child communication would have been strongly influenced in the first years after the divorce due to the required family restructuration and time of crisis at that moment (Lansford, 2009; Lewis et al., 2004). However, this result does not appear in our study, perhaps because all subjects in our sample had a process in Court (to custody regulation, or to amendment regulation, or to default custody process), regardless of how many years have passed since the divorce. In this sense, it is possible to conclude that all the participants of our subsample continue to experience crisis events related with child custody as the parents' inability to negotiate continues to be resolved in the Court (Bing et al., 2009). Regardless the years that have passed since the divorce, the subjects of our subsample continue in a restructuration stage (Ferraro et al., 2016). Although differences in years since divorce were not registered, a statistically significant difference was found related to the nature of the process, specifically, schoolaged children tend to perceive less availability of the mother to communicate in the custody regulation process compared to the other two analyzed processes (custody amendment process and default custody process). This 
result could be understood if we consider that the processes of custody regulation occur at an early stage of the divorce, that is, is the first process that succeeds the divorce decision.

\section{Limitations}

Although current and compelling, this study presents certain limitations that require caution with the generalization and discussion of the results. The literature indicates that the variable parental conflict most often predicts the well-being of the children/adolescents compared to the variable family composition (Bing et al., 2009). Thus, the inclusion of a measure to objectively assess the level of conflict between the parents in the studied samples would be useful to discuss the results. A second limitation of the present research is related to the length of the divorce/child custody processes. According to Afifi et al. (2014) and Lansford (2009), the age of the children/adolescents when their parents' divorce process begins is a critical variable to understand their adaptation to the event. In the present case of this research, and due to the difficulty in assembling a specific sample, the processes were selected with a wide range in terms of their start date (up to 10 years). In some cases, parents' divorce occurred more than a decade ago, a factor that may have influenced the results obtained, because in such circumstances, families had time to reorganize after the crisis (Lewis et al., 2004). Another limitation of the present study concerns the size of the sample. In general, each subsample has a reasonable size and equivalence to do some comparative statistical analysis; however, it cannot always maintain an appropriate number of subjects by category (e.g., family structure, nature of the divorce process). It is important to keep in mind the exploratory nature of this research and it is necessary to be cautious when generalizing results.

Despite the aforementioned limitations, the present study may offer a basis for further research. One suggestion for future research is to focus on the analysis of larger samples and also to develop and validate a theoretical model that facilitates a deeper understanding of the variables that could influence the relationship between parent-child communication and divorce. It would also be appropriate to collect new samples from families who are at the beginning of the divorce process and not in the custody process of the child. Finally, the promotion of longitudinal studies on the impact of divorce on communication characteristics has become a major challenge because it will allow a better understanding of the percentage of variation in communication explained by divorce before, during and after its occurrence.

Although the theoretical and empirical literature indicates that divorce is a disruptive event of parent-child relationships, the present study suggests that the communicational dimension may not be significantly affected. Parent-child communication seems to be a dimension with characteristics 
that are likely to be stable over several stages of the life cycle, as well as with critical events such as marital separation. Thus, the family structure may not be the most central variable for understanding family communication. In this sense, the data states that subjects from IN families may also have dysfunctional communication characteristics, just as subjects from PD families may have positive communication patterns. In accordance with the proposed premise Pragmatics of Human Communication (Watzlawick et al., 1967/ 1993), communication always exists as mediator of family relationships. What can really change is the contribution of its characteristics to the relationship. It is vital that clinicians and social work professionals can go beyond the labels and analyze how families work more widely and globally.

\section{Disclosure statement}

No potential conflict of interest was reported by the authors.

\section{Funding}

This study was funded by Science and Technology Foundation (grant number: SFRH/BD/ 63340/2009); Fundação para a Ciência e Tecnologia, Portugal.

\section{ORCID}

Alda Patrícia Marques Portugal (1) http://orcid.org/0000-0001-8951-2077

\section{References}

Afifi, T. D., Granger, D. A., Joseph, A., Denes, A., \& Aldeis, D. (2014). The influence of divorce and parents' communication skills on adolescents' and young adults' stress reactivity and recovery. Communication Research, 42(7), 1009. doi:10.1177/0093650213509665

Afifi, T. D., Huber, F. N., \& Ohs, J. (2006). Parents' and adolescents' communication with each other about divorce-related stressors and its impact on their ability to cope positively with the divorce. Journal of Divorce and Remarriage, 45(1/2), 1-30. doi:10.1300/ J087v45n01_01

Allen, J. P., \& Land, D. (1999). Attachment in adolescence. In J. Cassidy \& P. Shaver (Eds.), Handbook of attachment (pp. 319-335). New York, NY: Guilford Press.

Amato, P. R., Loomis, L. S., \& Booth, A. (1995). Parental divorce, marital conflict, and off-spring well-being during early adulthood. Social Forces, 73, 895-915. doi:10.1093/sf/ 73.3.895

Bing, N. M., Nelson, W., \& Wesolowski, K. L. (2009). Comparing the effects of amount of conflict on children's adjustment following parental divorce. Journal of Divorce and Remarriage, 50(3), 159-171. doi:10.1080/10502550902717699

Bornstein, M. H. (2002). Handbook of parenting - Volume 1. Children and parenting (2nd ed.). Mahwah, New Jersey: Lawrence Erlbaum Associates.

Carr, A. (2006). Family therapy. concepts, process and practice (2nd ed.). Chichester, England: John Wiley \& Sons. 
Cohen, O., Leichtentritt, R. D., \& Volpin, N. (2012). Divorced mothers' self-perception of their divorce-related communication with their children. Child and Family Social Work, 19, 34-43. doi:10.1111/j.1365-2206.2012.00878.x

Eldar-Avidan, D., Haj-Yahia, M. M., \& Greenbaum, C. W. (2009). Divorce is a part of my life ... Resilience, survival, and vulnerability: Young adults' perception of the implications of parental divorce. Journal of Marital \& Family Therapy, 35(1), 30-46. doi:10.1111/ jmft.2008.35.issue-1

Eurostat. (2018). Marriage and divorce statistics. Retrieved from https://ec.europa.eu/eurostat/ statistics-explained/pdfscache/6790.pdf

Ferraro, A. J., Davis, T. R., Petren, R. E., \& Pasley, K. (2016). Postdivorce parenting: A study of recently divorced mothers and fathers. Journal of Divorce and Remarriage, 57(7), 485-503. doi:10.1080/10502556.2016.1220302

Fitzpatrick, M. A., \& Marshall, L. J. (1996). The effect of family communication environments on children's social behavior during middle childhood. Communication Research, 23(4), 379-407. doi:10.1177/009365096023004003

Furstenberg, F. F., \& Nord, C. W. (1985). Parenting apart: Patterns of childrearing after marital disruption. Journal of Marriage and the Family, 47, 893-904. doi:10.2307/352332

Herbert, M. (2004). Parenting across the lifespan. In M. Hoghughi \& N. Long (Eds.), Handbook of parenting. Theory and research for practice (pp. 55-71). London, UK: Sage Publications.

Herzog, M. J., \& Cooney, T. M. (2002). Parental divorce and perceptions of past interparental conflict: Influences on the communication of young adults. Journal of Divorce and Remarriage, 36(3/4), 89-109. doi:10.1300/J087v36n03_06

Lambert, A. N. (2007). Perceptions of divorce advantages and disadvantages: A comparison of adult children experiencing one parental divorce versus multiple parental divorces. Journal of Divorce and Remarriage, 48(1/2), 55-77. doi:10.1300/J087v48n01_03

Lansford, J. E. (2009). Parental divorce and children's adjustment. Perspectives on Psychological Science, 4(2), 140-152. doi:10.1111/j.1745-6924.2009.01114.x

Laursen, B., \& Collins, W. A. (2004). Parent-child communication during adolescence. In A. Vangelisti (Ed.), Handbook of family communication (pp. 333-348). Mahwah, NJ: Lawrence Erlbaum Associates.

Lewis, J. M., Wallerstein, J. S., \& Johnson-Reitz, L. (2004). Communication in divorced and single-parent families. In A. Vangelisti (Ed.), Handbook of family communication (pp. 197-214). Mahwah, NJ: Lawrence Erlbaum Associates.

Linker, J. S., Stolberg, A. L., \& Green, R. G. (1999). Family communication as a mediator of child adjustment to divorce. Journal of Divorce and Remarriage, 30(1/2), 83-97. doi:10.1300/J087v30n01_06

Markham, M. S., Hartenstein, J. L., Mitchell, \& Aljayyousi-Khalil, G. (2017). Communication amog parents who share physiscal custody after divorce or separation. Journal of Family Issues, 38(10), 1414-1442. doi:10.1177/0192513X15616848

McHale, S. M., Crouter, A. C., \& Whiteman, S. D. (2003). The family contexts of gender development in childhood and adolescence. Social Development, 12(1), 125-148. doi:10.1111/sode.2003.12.issue-1

McManus, T. G., \& Nussbaum, J. F. (2011). Social support expectations and strategic ambiguity in parent-young adult child divorce-related stressor conversations. Journal of Divorce and Remarriage, 52(4), 244-270. doi:10.1080/10502556.2011.585083

McNaughton, J. (2000). Gender differences in parent-child communication patterns. Journal of Undergraduate Research, 3, 25-32.

Nunally, J. (1978). Psychometric theory. New York, NY: McGraw-Hill. 
Parra, A., \& Oliva, A. (2002). Comunicación y conflicto familiar durante la adolescencia. [Family communication and conflict during adolescence]. Anales De Psicologia, 18(2), 215-231.

Peck, J. S., \& Manocherian, J. R. (1995). O Divórcio nas Mudanças do Ciclo de Vida Familiar. In B. Carter \& M. McGolgrick (Eds.), As Mudanças no Ciclo de Vida Familiar. Uma estrutura para a terapia familiar [Changes in family life cycle. A structure to family therapy] (2a ed) (pp. 291-320). Porto Alegre, RS: Artes Médicas. (Original edition dates to 1989$)$.

Portugal, A., \& Alberto, I. (2013). Comunicação entre Pais e Filhos: Estudo das dimensões comunicacionais na relação parento-filial. [Parent-child communication: Study about communicational dimensions highlighted by parents and children]. Psicologia: Reflexão E Crítica, 26(3), 479-487. doi:10.1590/S0102-79722013000300007

Portugal, A., \& Alberto, I. (2014). Escala de Avaliação da Comunicação na Parentalidade (COMPA): Desenvolvimento e validação de uma medida da comunicação parento-filial. [Perception scale of parenting communication (COMPA): Development and validation of a parent-child communication measure]. Avances En Psicologia Latinoamericana, 32(1), 85-103. ISSN: e2145-4515. doi:10.12804/apl32.1.2014.06

Rivero-Lazcano, N., Martínez-Pampliega, A., \& Iraurgi, I. (2011). El papel funcionamiento y la comunicación familiar en los síntomas psicosomáticos. [The role of family functionning and communication in psychosomatic symptons]. Clínica Y Salud, 22(2), 175-186. doi: $10.5093 / \mathrm{cl} 2011 \mathrm{v} 22 \mathrm{n} 2 \mathrm{a} 6$

Segrin, C., \& Flora, J. (2005). Family communication. London, UK: Lawrence Erlbaum Associates.

Supratman, L. P. (2017). A changing paradigm of interpersonal communication in divorce family. SHS Web of Confereneces, 33, 1-5. doi:10.1051/shsconf/20173300042

Torres, A. M. C. (2010). Mudanças na Família. O Privado na Agenda Pública [Family changes: The privacy in public agenda]. Agregation exam in Sociology presented to Sociology Department of University Institute of Lisbon, Portugal.

Watzlawick, P., Beavin, J. B., \& Jackson, D. (1967/1993). Pragmatics of human communication: A study of international patterns, pathologies, and paradoxes. New York, NY: W. W. Norton \& Company.

Wilson, E. K., \& Koo, H. P. (2010). Mothers, fathers, sons, and daughters: Gender differences in factors associated with parent-child communication about sexual topics. Reproductive Health, 7, 31-39. doi:10.1186/1742-4755-7-31 